\title{
Measurement of Spleen Size at Laparoscopic Splenectomy
}

\author{
Cuneyt Kayaalp · Cemalettin Aydin · \\ Aydemir Olmez
}

Published online: 10 March 2009

(C) Société Internationale de Chirurgie 2009

\section{Dear Sir,}

We read with interest the article titled "Laparoscopic Versus Open Splenectomy for Nontraumatic Diseases" by Maurus et al. [1]. We have some comments, particularly regarding the measurement of the spleen size before and after surgery.

The authors reported that 9 of the 25 spleens (36\%) removed laparoscopically reached a volume of larger than 1 liter, and that 3 of their patients had spleens with volumes larger than 3 liters. They calculated the spleen volume by multiplying the length, width, and the depth of the spleen. Because the spleen is not a perfect rectangle, we do not think that correct spleen volume can be calculated by multiplying the dimensions of the organ. In fact, a calculation like this is likely to result in overestimation of the splenic volume. As the authors mentioned, calculation of the dimensions from the morcellated specimen will also result in questionable results. We think that generally accepted approaches to this measurement should be selected when studies based on spenic volume are being compared. Generally, spleen size before laparoscopic splenectomy can be estimated with largest diameter (usually craniocaudal length) or volumetry measurements by ultrasound or computed tomography [2, 3]. Postoperative size of splenectomy material is best measured by weight because the spleen is delivered in pieces [2, 4]. If necessary, postoperative volumetry for a solid organ can be calculated by the water overflow technique [5].

As a result of their calculations, the authors claimed that the previously suggested limit of $1 \mathrm{~kg}$ as the cutoff for laparoscopic surgery could be ignored and should not be a reason to abstain from a laparoscopic procedure. We think that before making such a specific recommendation, measurement of the spleen sizes should be more realistic.

\section{References}

1. Maurus CF, Schafer M, Muller MK et al (2008) Laparoscopic versus open splenectomy for nontraumatic diseases. World J Surg 32:2444-2449

2. Habermalz B, Sauerland S, Decker G et al (2008) Laparoscopic splenectomy: the clinical practice guidelines of the European Association for Endoscopic Surgery (EAES). Surg Endosc 22: 821-848

3. Lamb PM, Lund A, Kanagasabay RR et al (2002) Spleen size: how well do linear ultrasound measurements correlate with threedimensional CT volume assessments? Br J Radiol 75:573-577

4. Aydin C, Kayaalp C, Olmez A et al (2008) Laparoscopic splenectomy with a vessel sealing device. Minim Invasive Ther Allied Technol 17:308-312

5. Kayaalp C, Arda K, Oto A et al (2002) Liver volume measurement by spiral CT: an in vitro study. Clin Imaging 26:122-124
C. Kayaalp $(\varangle) \cdot$ C. Aydin · A. Olmez

Department of General Surgery, Inonu University, Malatya, Turkey

e-mail: cuneytkayaalp@hotmail.com 